\title{
Mapping a nation's landslides: a novel multi-stage methodology
}

\author{
Hannah Evans $^{(1)}$, Catherine Pennington $^{(1)}$, Colm Jordan $^{(1)}$, Claire Foster $^{(1)}$
}

(1) British Geological Survey, Keyworth, Nottingham, NG12 5GG, UK, hann@bgs.ac.uk

\begin{abstract}
Through combining new technologies and traditional mapping techniques, the British Geological Survey (BGS) has developed a novel, multi-stage methodology for landslide mapping. 3-D aerial photograph interpretation, variable-perspective 3-D topographic visualisation and field mapping with digital data capture are being used to map the UK's landslides. The resulting ESRI ArcGIS polygons are published on BGS 1:50,000 geological maps and as digital data products. Data collected during mapping are also uploaded directly into the National Landslides Database maintaining a systematic, nationally-uniform landslide inventory. Repeat monitoring of selected landslides using terrestrial LIDAR and dGPS allows the database to be frequently updated and the proactive Landslide Response Team means that new landslide events can be mapped within days, if not hours, of their occurrence. The long-term aim is to apply this methodology throughout the UK, providing a wealth of data for scientific research and hazard assessment. This methodology is also suitable for application in an international context.
\end{abstract}

Keywords landslide mapping, hazard assessment, 3-D visualisation, digital data capture

\section{Introduction}

When examining the pre-conditioning and triggering factors required to generate a landslide (Fig 1), the UK at first appears to be at a relatively low risk of landslide events. The country is largely unaffected by the extreme climatic and tectonic events experienced elsewhere in the world and the role of such major landslide-inducing factors as earthquakes, rainfall and changes in water level is less extreme than in the global context. However, the densely populated nature of the country combined with an abundance of relict landslides means that landslide research in the UK is paramount. Furthermore, heightened anthropogenic activity witnessed in the UK over the last few decades has added a new dimension to the landslide pre-conditioning and triggering factors, increasing the likelihood of landslide events, both through new failures and the reactivation of existing features.

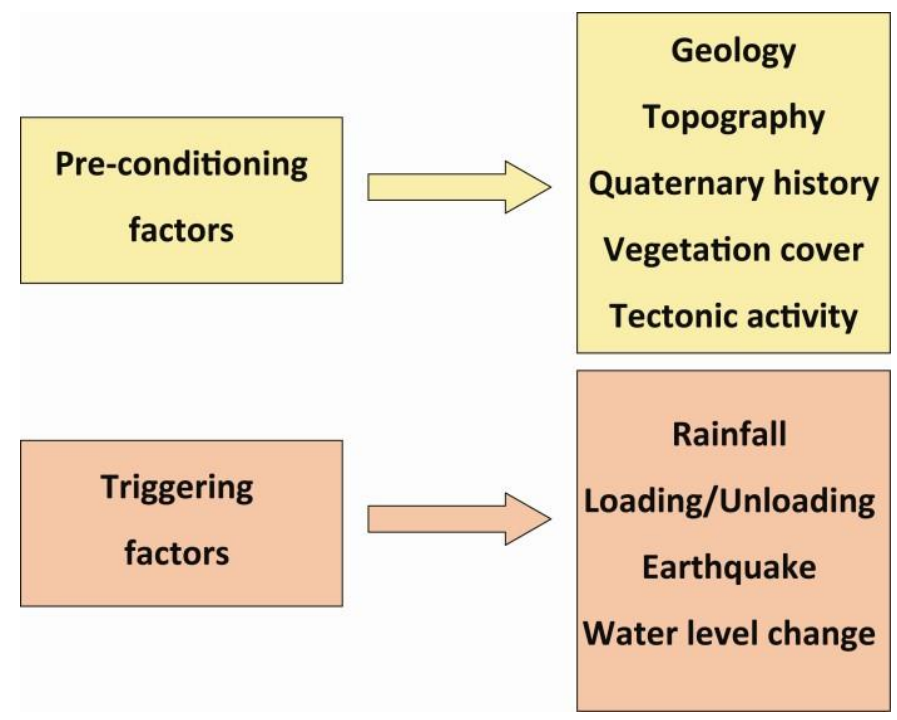

Figure 1 Selected landslide pre-conditioning and triggering factors. 
Since the 1930s the British Geological Survey (BGS) has been engaged in the mapping and inventory of landslides across the UK. The BGS uses a modified version of the landslide classification schemes detailed in Varnes (1978), Flageollet (1993) and WP/WLI (1990). Five main landslide types are recognised (falls, flows, topples, slides and spreads) occurring as single, multiple, complex or composite events. Landslides with a discernable back scar and a zone of deposition are considered as mappable units. As defined by McMillan and Powell (1999) there are four types of mass movement deposit: landslide, talus, head and dry valley deposits. Mass movement deposits where the origin of the feature cannot be reliably attributed to landslide processes are not mapped in the landslide surveys.

Recent technological developments have been combined with traditional mapping techniques to develop the novel multi-stage methodology described in this paper. This methodology is applied through the combination of strategic, repeat and responsive landslide surveys carried out by the BGS. The long-term aim of this research is to allow the BGS to better characterise and understand the country's landslides by investigating the links between geology, geomorphology and palaeoenvironmental evolution. This will facilitate hazard assessment and infrastructure planning as well as informing the UK's landslide susceptibility model. Sections of the methodology have also been applied further afield in an international context.

The BGS's landslide mapping methodology

A range of complementary techniques is employed by the BGS to map the UK's landslides. Prior to commencing a strategic field survey a desk-based interpretation is made using visualisation and photogrammatic software. In the field digital data capture is used to aid mapping speed and accuracy, whilst the existence of the BGS Landslide Response Team allows rapid mobilisation to record new events. Repeat surveys of selected active landslides are also undertaken in order to provide data in 4-D. The data captured is then stored in a range of formats: as attributed georeferenced ESRI ArcGIS polygons published on BGS 1:50,000 and 1:10,000 scale geological map sheets and as BGS DiGMap50 and DiGMap10 digital data products as well as attributed point data in the BGS National Landslide Database (NLD). The individual mapping techniques and data storage mechanisms are detailed below:

\section{3-D aerial photograph interpretation}

The distinct morphology created by landslides, such as hummocky terrain, arcuate scarps and tension cracks, can often be readily identifiable from aerial photographs (Mantovani et al., 1996; Mason and Rosenbaum, 2002). At a scale of 1:50,000 aerial photographs allow detection of objects as small as $7.5 \mathrm{~m} \times 7.5 \mathrm{~m}$ and the minimum detectable size decreases with increased photograph resolution (Tribe and Leir, 2004). Prior to commencing a strategic landslide field survey the BGS uses SOCET for ArcGIS software for 3-D visualisation of georeferenced colour vertical aerial photographs of the area concerned. Draft georeferenced ESRI ArcGIS polygons are derived by digitising around the landslide deposits identified in a linked digital stereoscope and ESRI ArcGIS environment. These polygons are assigned $\mathrm{X}, \mathrm{Y}$ and $\mathrm{Z}$ dimensions by combining the horizontal georeferencing information with $\mathrm{Z}$ values assigned from an underlying digital elevation model.

\section{Variable-perspective 3-D visualisation of topographic features}

Developed jointly by the BGS and Virtalis Ltd., Geovisionary ${ }^{\mathrm{TM}}$ visualisation and photogrammetric software provides seamless streaming of aerial photographs, topographic maps, geological models and other GIS data into a 3D terrain which can be viewed in stereo. In addition, Geovisionary ${ }^{\mathrm{TM}}$ allows the user to fly through a 3D photo-realistic rendered view of the data and is often used to provide an additional perspective not available through the use of SOCET for ArcGIS software. When used in landslide mapping campaigns, this allows a range of resources to be interrogated and landslide 
deposits to be digitised as georeferenced ESRI ArcGIS polygons prior to the field survey. BGS geological maps, historical topographic maps, and existing literature are also consulted to augment data gathered during the 3-D visualisation stages.

\section{Field mapping with digital data capture}

BGS•SIGMAmobile was developed by the BGS to provide an integrated field mapping software system with graphical map interface tools, free text and structured input using drop-down menus (downloadable for free from www.bgs.ac.uk/research/technologies_epo.html). Ruggedised tablet PCs carrying BGS•SIGMAmobile allow the ESRI ArcGIS polygons digitised during the desk-based interpretation to be taken into the field along with the full suite of pre-existing data (Fig 2). Any modifications to the landslide deposit polygons required following field validation can, therefore, be performed at the landslide site. A bespoke digital landslide proforma has also been incorporated into the system in order to aid the systematic and comprehensive recording of attributed point data for input into the NLD. In addition to this, ancillary data such as digital photographs can be spatially linked to the landslide data and annotated as required.

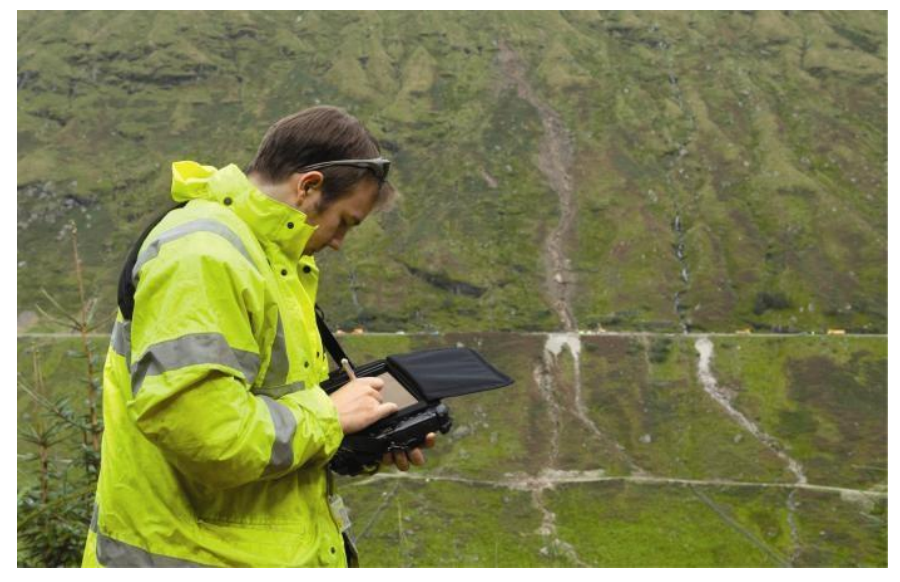

Figure 2 BGS landslide survey using a ruggedised tablet PC with BGS•SIGMAmobile.

\section{Repeat terrestrial LIDAR and dGPS surveys}

In addition to strategic field surveys, the BGS has performed repeated monitoring of selected landslides using terrestrial laser scanning (LIDAR) for the last 9 years (Fig 3). Terrestrial LIDAR works by measuring the relative distance, elevation and azimuthal angles between the laser scanner and landslide and, when georeferenced with differential GPS (dGPS), a 3-D surface model can be generated (Hobbs et al. 2002; Rowlands et al. 2003). Analysis of repeated scans over regular time intervals can accurately determine, for example, the nature of the landslide processes (Hobbs et al. 2010). A high resolution digital camera mounted onto the scanner enables coloured point-clouds, textured triangulated surfaces or orthophotos with depth information to be captured. Landslides routinely visited by the BGS include the Hollin Hill Landslide Observatory, Terrington, North Yorkshire (Chambers et al. 2011) and that at Happisburgh, Norfolk. Insights into landslide processes gained from these repeat surveys are used to supplement those at the national scale derived from BGS strategic surveys. 


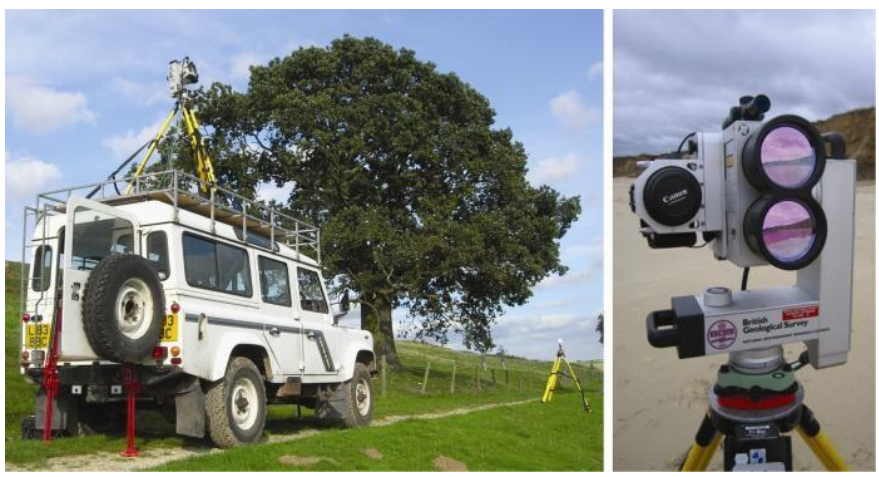

Figure 3 The BGS Riegl LPM-i8ooHA laser scanner which can achieve an accuracy of $\pm 15 \mathrm{~mm}$.

\section{Landslide response}

The BGS has established a 24-hour on-call Landslide Response Team that can respond quickly to new landslide events, allowing them to be mapped within days, if not hours, of their occurrence. This is vital given the relatively low preservation potential of landslide deposits in areas with increased anthropogenic activity. Responsive landslide surveys are triggered through daily email alters from online news searching services, media reports and public enquiries. On mobilisation to the landslide site the team gathers geomorphological and process information about the new landslide to update the BGS geological maps and digital data products; enter data into the NLD and to provide, where possible, an immediate impartial assessment of the cause, state and potential for further landslide movement. Terrestrial LIDAR scanning and dGPS surveys can also be employed in these responsive situations. To-date the BGS has visited landslides throughout the UK, including the Rest and $\mathrm{Be}$ Thankful Landslide, Argyll, Scotland; Black Ven Landslide, Dorset, England and; Oxwich Bay Landslide, Swansea, Wales (www.bgs.ac.uk/landslides/casestudies.html).

\section{National Landslide Database}

The BGS runs the definitive source of information on British landslides: the NLD. The database currently holds over 15,000 records and provides a systematic, nationallyuniform inventory of the UK's landslides. Each record can hold information on over 35 attributes including location, dimensions, failure type, causal mechanisms, damage, geology, hydrogeology and a full bibliographic reference. The database is linked to a GIS which displays the landslide events as point data. Data come from a variety of sources including published BGS geological maps; BGS strategic, repeat and responsive surveys; existing literature and media reports. The database is dynamic and new records are continuously added. Selected information from the NLD is now freely available through the BGS's online GIS- Geolndex (www.bgs.ac.uk/geoindex/).

\section{BGS strategic, repeat, responsive and international landslide surveys}

To-date the novel landslide mapping methodology developed by the BGS has been applied to several UK locations. The on-going aim is to extend this methodology throughout the nation in order to provide a definitive survey and inventory of UK landslides. The methodology described herein has also been trialled in selected international contexts. Detailed examples of the application of this methodology are given below:

\section{Strategic landslide survey}

Continuing a series of strategic landslide mapping programmes, the BGS is currently mapping landslides in the North York Moors, Yorkshire. 3-D aerial photograph interpretation was used to derive georeferenced ESRI ArcGIS polygons for validation in the field. A total of 302 potential landslide polygons were to be investigated across the area covered by the Egton and Guisborough BGS 1:50,000 
map sheets. Preliminary results show two main types of failure in the area: large-scale, deep-seated multiple rotational or translational failures and smallerscale, shallow earth flows or translational slides. The degree of degradation and geomorphology of the largescale, deep-seated features suggest development under periglacial conditions, last experienced in the area during the Pleistocene, whilst the smaller-scale features and impact on archaeology implies a maximum age of approximately 200500 years for the small-scale earth flows and translational slides. Examination of the relationship between landslide location, geology and slope angle demonstrates a clustering of landslide around structurally weaker geological units such as the Jurassic Whitby Mudstone Formation (Lias Group) and higher slope angles (Fig 4).

\section{Repeat landslide survey}

Since 2006 the BGS has undertaken annual terrestrial LIDAR and dGPS surveys at the Hollin Hill Landslide Observatory, Terrington, North Yorkshire. This active inland landslide displays multiple headscarps, flows and toe lobes across a series of geological benches within an area of approximately $300 \mathrm{~m} \times 250 \mathrm{~m}$. Elevation change models derived from re-occupation of identical scan positions year on year reveal zones of depletion and accumulation. Changes in the range of $\pm 2 \mathrm{~m}$ are not uncommon throughout the downslope portion of the landslide (Fig 5).

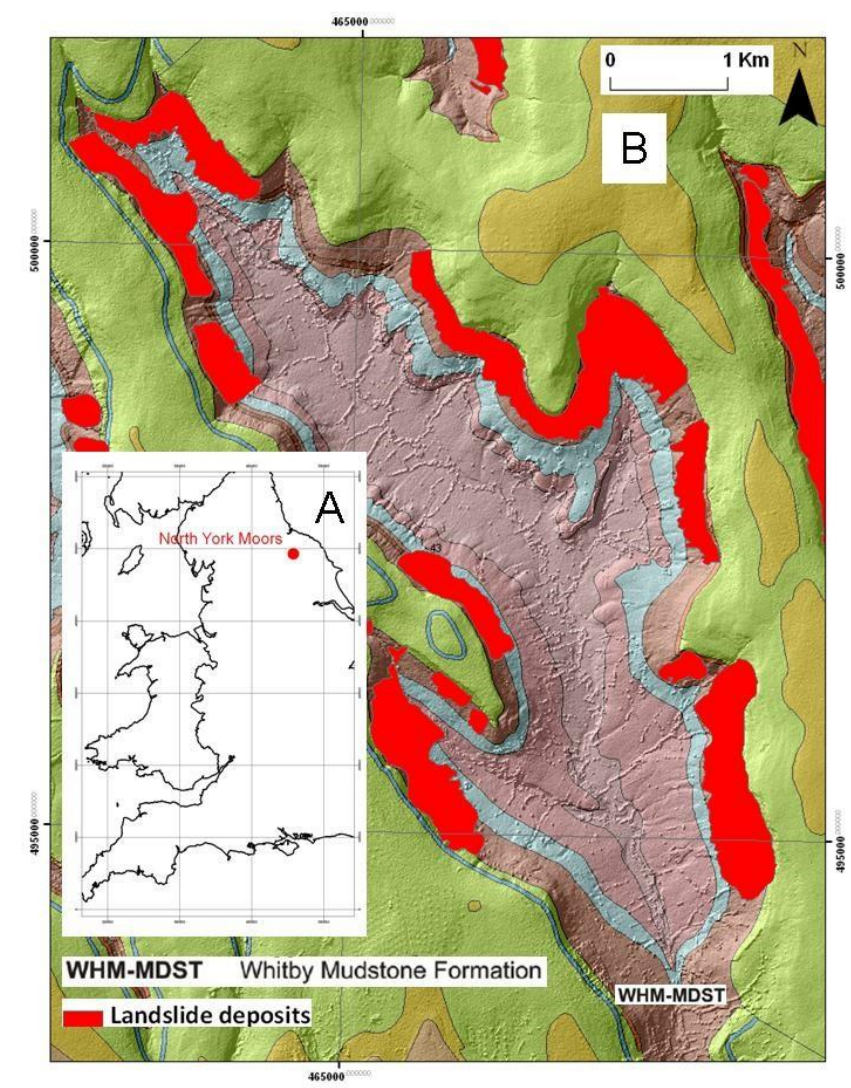

Figure 4 BGS strategic landslide survey of the North York Moors, UK: (A) location of the study area, (B) clustering of landslides in areas of increased slope angle and weaker lithologies, Farndale, North York Moors, UK. NEXTMap Britain elevation data from Intermap Technologies. 


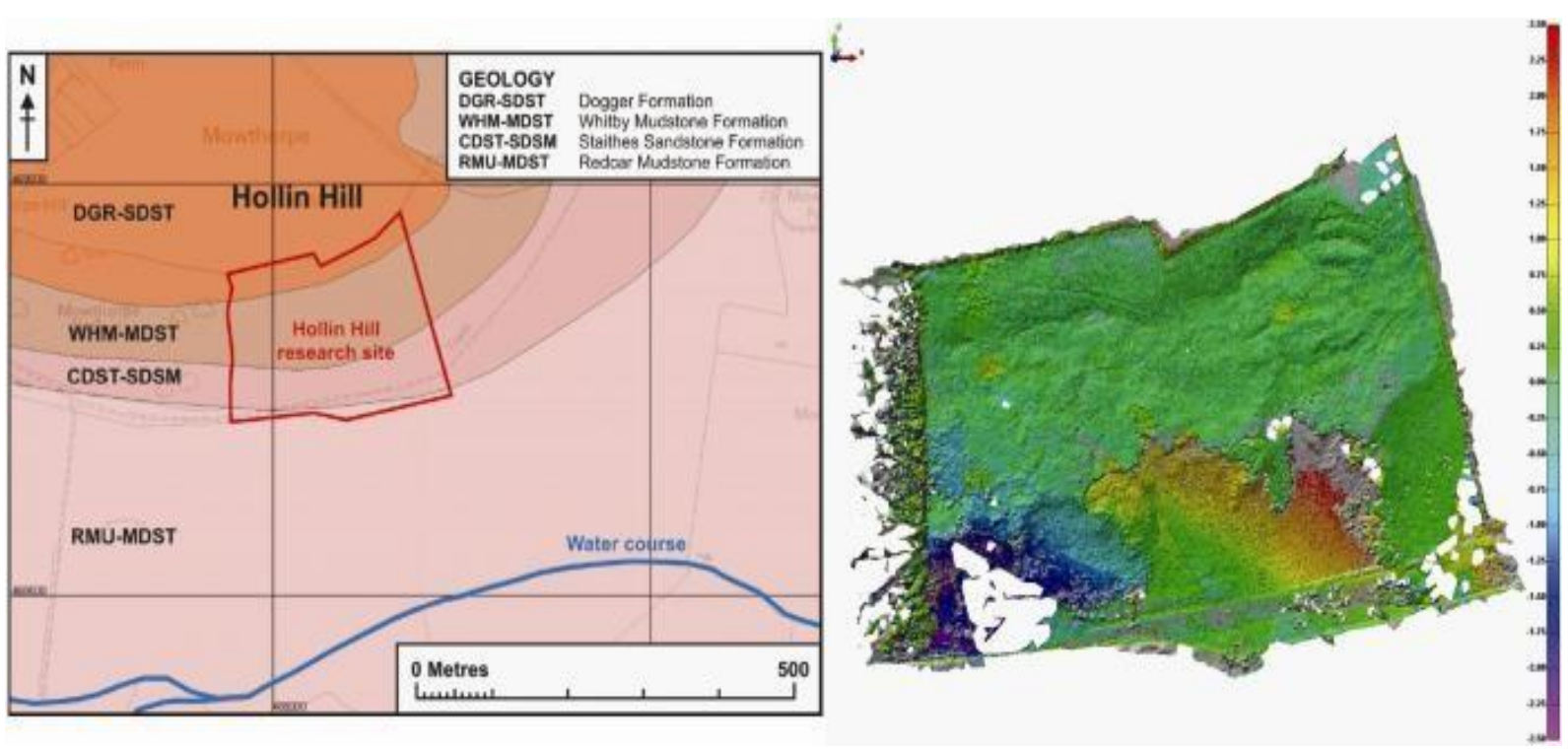

Figure 5 BGS repeat landslide survey of the Hollin Hill Landslide, Yorkshire: (Left) geological conditions at the study site after Chambers et al. (2011), (Right) terrestrial LIDAR elevation change model for 2006-2007.

\section{Responsive landslide survey}

In May 2008 the BGS Landslide Response Team was alerted to the reactivation of a portion of the Black Ven Landslide, Lyme Regis, Dorset (Fig 6). This landslide is one of the largest and most studied in the UK but the mechanisms of failure are so complex that debate continues as to the exact causal processes. The reactivation was widely reported in the national media amid fears that a triggering of the whole complex would follow. The BGS undertook a field survey with digital data collection using BGS•SIGMAmobile software. Data was gathered in order to update the BGS 1:50 000 and 1:10 000 scale geological maps, DiGMap50 and DiGMap10 digital data products and the NLD. In addition, a terrestrial LIDAR and dGPS survey was conducted and digital terrain model of the failure developed.

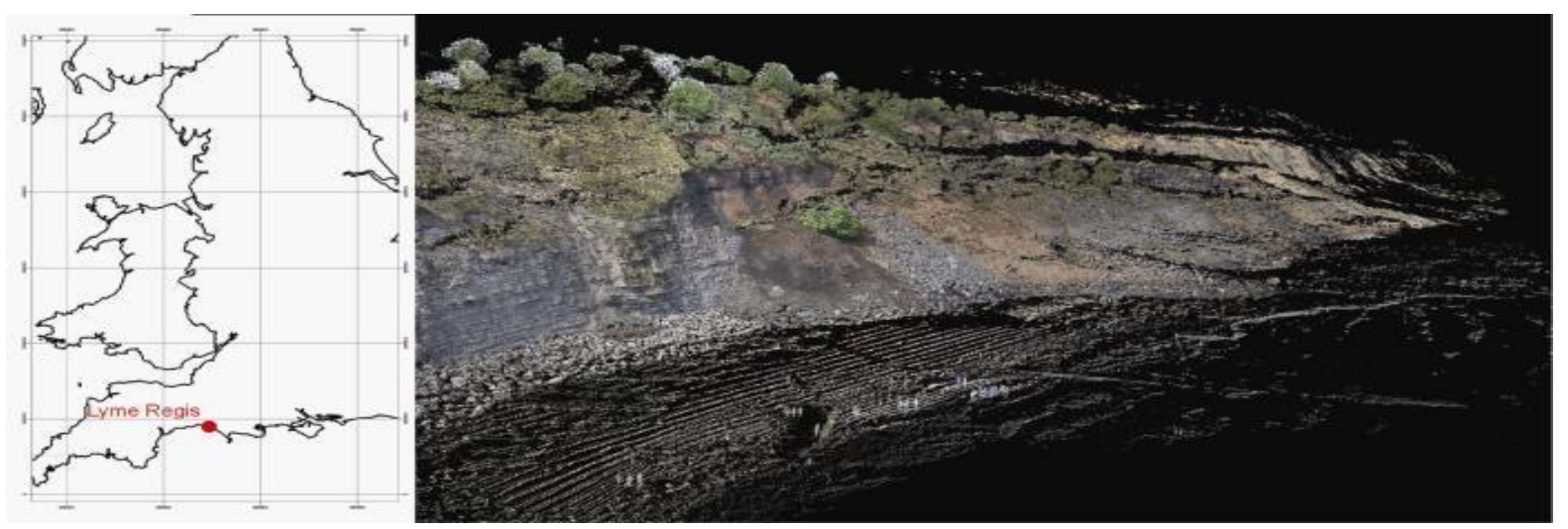

Figure 6 BGS responsive survey of the May 2008 reactivation at the Black Ven Landslide Complex, Lyme Regis, Dorset, UK: (Left) location of the Black Ven Landslide, (Right) terrestrial LIDAR point cloud of the May 2008 reactivation zone.

\section{International survey}

In February 2005 the BGS was funded by the World Bank to undertake a three year geological and geomorphological mapping project in Madagascar. A major constituent of the commissioned geomorphological maps, which covered an area of $250,000 \mathrm{~km}^{2}$ at a scale of $1: 500,000$, was delineation of the recent and extensive landsliding, known as lavaka. With such a short time scale available to map a large area with a poor road network, a combination of efficient image 
interpretation and focussed field mapping was called for. SOCET for ArcGIS and Geovisionary ${ }^{\mathrm{TM}}$ allowed rapid landform mapping, whilst the imagery and resulting linework taken to Madagascar on BGS•SIGMAmobile enabled focussed field research.

Further afield, BGS undertook a pilot geological mapping project, funded by the European Space Agency, demonstrating how modern digital workflows can be applied to the geological and geomorphological mapping of Mars. With collaborators in the Netherlands Organisation for Applied Scientific Research/ Deltares, Geological Survey of the Netherlands and University College London, the team used SOCET for ArcGIS and Geovisionary ${ }^{\mathrm{TM}}$ software to successfully interpret a range of remotely sensed imagery. The landscape on Mars contains landforms that are significantly larger than those found on Earth, with landslide dimensions of, for example, $5 \mathrm{~km} \times 70 \mathrm{~km}$ (Fig 7). The use of systems like Geovisionary ${ }^{\mathrm{TM}}$ to quickly and efficiently analyse vast landscapes is a major benefit, especially when fieldwork is impractical.

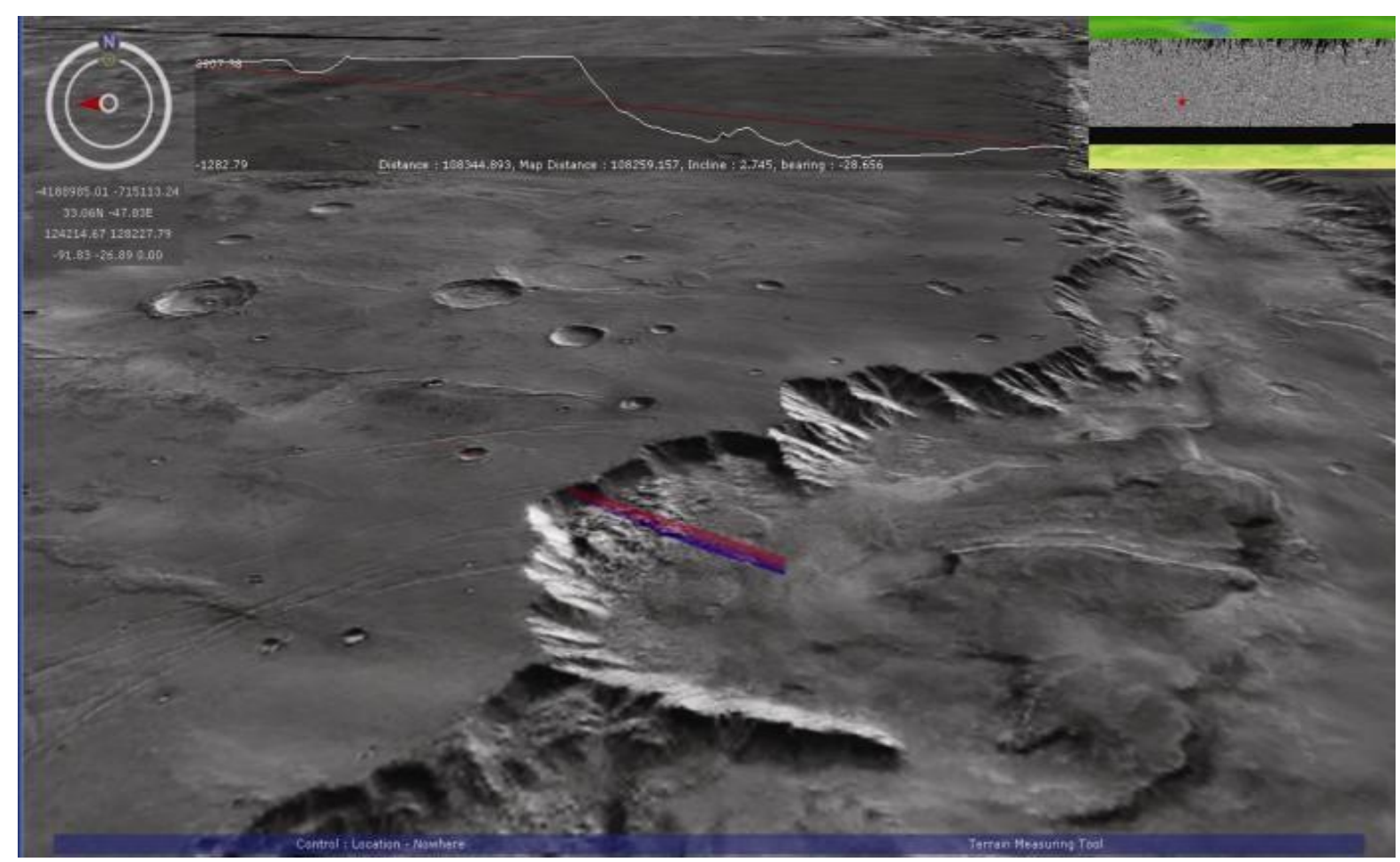

Figure 7 Geovisionary ${ }^{\mathrm{TM}}$ visualisation of a landslide on Mars looking west along the Valles Marineris to Melas Chasmas using MOLA and THEMIS data. Raw imagery from NASA.

\section{Conclusions}

The BGS has developed a novel, multi-stage methodology for landslide mapping and inventory within the UK. This methodology blends new technologies and traditional mapping practices to include six complementary mapping techniques and three data storage and presentation mechanisms. BGS is unique in the UK in that it possess the capability to study landslides at the national and regional scales and its long-term aim is to apply this methodology throughout the UK in order to better understand and characterise the nation's landslides. This will provide a wealth of data for scientific research, hazard assessment and infrastructure planning as well as informing a landslide susceptibility model of the UK. To-date the methodology has been rolled out across a number of BGS 1:50,000 map sheets through strategic field surveys and applied to numerous individual inland and coastal landslides through repeat and responsive field surveys. The methodology is also suitable for application in an international context and aspects of the process have already been trialled in Madagascar and applied to Martian landslides. Development of the BGS landslide mapping methodology is an on-going 
process and continued technological developments for example, advances in remote sensing, digital data capture and data visualisation technologies, will be incorporated where possible.

\section{Acknowledgements}

The authors publish with the permission of the Executive Director of the British Geological Survey (Natural Environment Research Council). The National Grid and other Ordnance Survey data are used with the permission of the Controller of Her Majesty's Stationery Office. Licence No: 100017897/2010. Mars data acquired by D. Tragheim (BGS).

\section{References}

Chambers J E, Wilkinson P B, Kuras O, Ford J R, Gunn D A, Meldrum P I, Pennington C V L, Weller A L, Hobbs P R N, Ogilvy R D (2011). Three-dimensional geophysical anatomy of an active landslide in Lias Group mudrocks, Cleveland Basin, UK. Geomorphology.. 125(4): 472-484.

Hobbs P R N, Gibson A D, Jones L, Pennington C V L, Jenkins G, Pearson S G, Freeborough K A (2010) Monitoring coastal change using terrestrial LiDAR. In: Fleming C, Marsh S H, Giles J R A, (eds). Elevation Models for Geoscience. Special Publications 345. Geological Society: London, pp. 117-127.

Hobbs P, Humphreys B, Rees J, Tragheim D, Jones L, Gibson A, Rowlands K, Hunter G, Airey R (2002) Monitoring the role of landslides in 'soft cliff' coastal recession. In: Mclnnes R G, Jakeways J, (eds). Instability Planning and Management. Thomas Telford: Isle of Wight, pp. 589-600.

Mantovani F, Soeters R, Van Westen C J (1996) Remote sensing techniques for landslide studies and hazard zonation in Europe. Geomorphology. 15: 213-225.

Mason P, Rosenbaum M S (2002) Geohazard mapping for predicting landslides: the Langhe Hills in Piemonte, NW Italy. Quarterly Journal of Engineering Geology \& Hydrology. 35(4): 317-326.

McMillan A A, Powell J P (1999). BGS Rock Classification Scheme Volume 4. Classification of artificial (man made) ground and natural superficial deposits- applications to geological maps and datasets in the UK. British Geological Survey Research Report RR 99-04. HMSO: London. 66p.

Rowlands K, Jones L, Whitworth M (2003) Photographic Feature: Landslide Laser scanning: a new look at an old problem. Quarterly Journal of Engineering Geology. 36(2): 155-158.

Tribe S, Leir M (2004) The role of aerial photograph interpretation in natural hazard and risk assessment. Proceedings of the International Pipeline Conference, October 2004, Calgary, Alberta, Canada. 6p.

Varnes D J (1978) Slope movements types and processes. In: Schuster R L, Krizek R J (eds). Landslides: Analysis and Control. Transportation Research Board, National Academy of Sciences, Washington D.C., Special Report, No. 176. pp. 11-33.

WP/WLI (1990) International Geotechnical Societies' UNESCO Working Party on World Landslide Inventory: A suggested method for reporting a landslide. Bulletin of the International Association of Engineering Geology. 41: 5-12. 